\title{
THE EFFECTS OF UTILIZATION OF SOCIAL MEDIA BY WORKERS ON LABOR LAW
}

\author{
DOI: 10.17261/Pressacademia.2018.919 \\ PAP- V.7-2018(72)-p.372-375
}

Yeliz Bozkurt Gumrukcuoglu

Ibn Haldun University Law School, Istanbul, Turkey.

yeliz.bozkurt@gmail.com, ORCID: 0000-0003-2589-0305

To cite this document

Gumrukcuoglu, Y. B. (2018). The effects of utilization of social media by workers on labor law. PressAcademia Procedia (PAP), V.7, p.372-375. Permemant link to this document: $\mathrm{http}: / /$ doi.org/10.17261/Pressacademia.2018.919

Copyright: Published by PressAcademia and limited licenced re-use rights only.

\section{ABSTRACT}

Purpose- The aim of this study is to examine the use of social media, which leads to legal problems in all phases beginning from the recruitment process of the workers up to termination of their employment relations.

Methodology- In our study the problems faced in implementation will be tried to be assessed within the framework of relevant legislative regulations and court practices by comparing them with the practice of European Union.

Findings- According to the findings, using the social media at the workplace, within working hours may lead to problems regarding the work performance and problems might be encountered due to the utilization of social media out of working hours by using the computer, IP address, workplaces' account or internet access.

Conclusion- According to the results of the study; related to the use of social media in workplace appropriate legislation and workplace policies should be developed.

Keywords: Social media, labor law, recruitment, working relation, termination.

JEL Codes: K31, J83, J81

\section{işÇiNIN SOSYAL MEDYA KULLANIMININ IŞ HUKUKUNDAKi ETKILERI}

\section{ÖZET}

Amaç- Bu çalışmanın amacı, işe alım süreçlerinden iş ilişkilerinin sona ermesine kadar tüm aşamalarda iş hukuku açısından yasal sorunlara yol açan sosyal medyanın kullanımını incelemektir.

Yöntem- Çalışmamızda, uygulamada karşılaşılan problemler, konuya ilişkin yasal düzenlemeler ve içtihatlar çerçevesinde, Avrupa Birliği uygulamasıyla karşılaştırılarak değerlendirilmeye çalışılacaktır.

Bulgular- Elde edilen bulgulara göre işyerinde, iş saatlerinde gerçekleştirilen kullanımlar iş görme ediminin ifasında sorunlara yol açabilirken, iş saatleri dışında da olsa işverene ait bilgisayar, ID adresi, işyeri hesabının veya internet erişiminin kullanımına bağı problemlerle karşılaşılmaktadır.

Sonuç- Bu çalışmanın sonuçları çerçevesinde işyerinde sosyal medya kullanımına ilişkin olarak yasal mevzuatın geliştirilmesi gerektiği ve işyerlerinde uygun politikalar belrilenmesi gerektiği ifade edilmelidir.

Anahtar Kelimeler: Sosyal medya, iş hukuku, işe alım, iş ilişkisi, fesih.

JEL Kodları: K31, J83, J81

\section{GiRiş}

Teknolojik gelişime bağlı olarak ülkemizde bilgisayar ve internet ve sosyal medya kullanımında da ciddi bir artış görülmektedir. Genel anlamı ile "sosyal medya"yı kullanıcıların medya içeriği hakkında bilgi alışverişinde bulundukları ve yorum yaptıkları sosyal ağlardaki çevrimiçi etkinlikler olarak tanımlamak mümkündür (https://www.gruenderszene.de/lexikon/begriffe/social-media E.T. 01.03.2018). Sanal kaytarma davranışları gün geçtikçe artmaktadır ve bu davranışlar içerisinde de sosyal medya kullanımı önemli bir yer teşkil etmektedir. İşyerinde ara dinlenmelerinde ve mesai saatleri içerisinde kişisel amaçlarla sosyal medya kullanımı hatta iş dışı zamanlarda gerçekleşen kullanımın iş ilişkisine yansımaları söz konusu olabilmektedir. Kanaatimizce, ilerleyen dönemde sosyal medya kullanımının iş ilişkisine yansımalarına ilişkin yargıya yansıyan sorunlar gün geçtikçe daha da artacaktır. Çalışmamızda, iş ilişkisinin kurulmasına ilişkin süreçten başlayarak sosyal medya kullanımının iş ilişkisine etkileri bireysel iş hukuku temelinde değerlendirilecektir. 


\section{LITERATÜR INCELEMESI}

Günümüzde işverenlerin işe alım kararı vermelerinde önemli faktörlerden biri de adaya ilişkin sosyal medya bilgileridir. İşverenlerin adaya ilişkin sosyal medya araştırması yapma nedenlerinden biri sosyal medyada herkese açık yayınlanan bilgilerde daha az yalana başvurulması diğeri adaya ilişkin hızlı ve düşük maliyetli bir araştırma olanağı vermesidir. İşverenin işe alım kararına etki eden faktörler adayın mesleki yeterliliklerinden ibaret değildir. İşverenin adaya ilişkin bilgi edinme ve görüşmelerde soru sorma hakkının sınırsız olmadığı, yöneltilen soruların adayın mesleki yaşamı ile ilgili olması ve kişilik haklarını ihlal etmemesi gerektiği kabul edilmektedir (Güzel, 1996: 187; Aydınlı, 2014: 29). Adayın işe ilişkin olmayan, kişilik haklarını ihlal eden yahut ayrımcılık yasağına aykırılık teşkil eden soruları yanıtlamama veya doğru yanıtlamama hakkı vardır. Ancak işverence sosyal medya üzerinden yapılacak araştırmalarda bu esaslara aykırılık teşkil eden bilgilere erişim sağlanması da mümkün olabilecektir. Örneğin, kural olarak işin niteliği ve özelliği gerektirmedikçe işçiye hamileliğe ilişkin soru yöneltilmemesi gerekmektedir (Eyrenci, 1991: 254; Ertürk, 2002: 73; Gürsel, 2016a: 811). Adaya ilişkin kişisel verilerin sosyal medya araştırmasıyla edinilmesi ve işlenmesi durumunda kişisel verilerin korunması hukuku açısından da çeşitli problemlerle karşılaşılmaktadır. Kanaatimizce, işveren tarafından arama motorları yahut sosyal medya araştırmalarıyla elde edilen verilerin işlenmesinde adayın rızası olduğu ve bu verilerin adayın bilgisi dışında işlenebileceği kabul edilemez (Sholz, 2016: § 32 BDSG, Rn. 9). Kişisel Verilerin Korunması Kanunu'nun (KVKK) 5. maddesine göre, kişisel veriler ilgili kişinin açık rızası olmaksızın işlenemez. Ancak, hukuka uygunluk sebeplerinin varlığı halinde kişisel verilerin açık rıza aranmaksızın işlenebilecektir. İşlenecek verinin sözleşmenin kurulmasıyla doğrudan ilgili olması ya da adayın kendisi tarafından alenileştirilmiş olması durumunda hukuka uygun olduğu kabul edilebilecektir. Ancak, kanaatimizce işverence internette arama motorları veya sosyal medya hesapları aracılığı ile yapılan araştırmalar neticesinde elde edilen her türlü kişisel verinin, adayın alenileştirmesi dolayısıyla işlenebileceği kabul edilemez. TBK m. 419'a göre, "İşveren, iş̧̧iye ait kişisel verileri, ancak işçinin işe yatkınlığıyla ilgili veya hizmet sözleşmesinin ifası için zorunlu olduğu ölçüde kullanabilir.”. Bu çerçevede işverenin sosyal medya üzerinden hukuken uygun olmayan bilgileri edinerek işlemesi mümkün değildir. KVKK m. 4'e göre de, kişisel verilerin, hukuka ve dürüstlük kurallarına uygun, doğru ve gerektiğinde güncel, belirli, açık ve meşru amaçlarla, işlendikleri amaçla bağlantılı, sınırlı ve ölçülü şekilde işlenmesi ve ilgili mevzuatta öngörülen veya işlendikleri amaç için gerekli süre kadar muhafaza edilmesi gerekir. Aday tarafından alenileştirilmiş olsa da bilgisi verilmeden işleme yapılmamalıdır. Bu açıdan önem arz eden bir diğer husus, verinin kim tarafından alenileştirildiğidir. Bu paylaşımların bir kısmı bireyin örtülü de olsa rızasına dayanırken, bazıları tamamen rıza dışında gerçekleşebilmektedir. Bunun yanı sıra, adayın temel hak ve özgürlüklerine zarar vermemek kaydıyla, veri sorumlusunun meşru menfaatleri için veri işlenmesinin zorunlu olması işveren açısından bir hukuka uygunluk sebebi teşkil edebilecektir. KVKK m. 6 kapsamındaki özel nitelikli veriler ise bu açıdan ayrı tutulmalıdır. Bunlar, nitelikleri gereği kanun koyucu tarafından daha güçlü bir korumaya tabi tutulmuş olup, bu nitelikteki verilerin işlenebilmesi, veri sahibinin açık rızası veya kanunlarda öngörülen hallerde mümkündür. Sağlık ve cinsel hayata ilişkin verilerin işlenmesi ise özel olarak düzenlenmiştir. Hukuka uygunluk nedenlerinin varlığı halinde de veri sorumlusunun yasal yükümlülüklere uygun davranması ve veri sahibin yasal haklarını kullanabilmesine olanak sağlar şekilde veri işlemesi gerekir.

İşyeri bilgisayarlarının ve internet bağlantısının kişisel amaçlarla kullanımı veya sosyal medya paylaşımları işveren açısından, iş gücü kaybı, virüs bulaşma ihtimali, prestij kaybı, kurumsal kimliğin zarar görmesi, telif haklarının bu araçlarla ihlali, suç teşkil eden eylemlere karışma, pornografik erişim, çocuk pornosu erişimi, işletme sırlarının öğrenilebilmesi ya da hukuka aykırı aktarımı vb. riskler doğurabilmektedir. İşçinin iş görme edimini ifasına ilişkin olmayan kullanım kişisel kullanım olarak nitelendirilmektedir (Okur, 2011: 147). Bu gibi davranışların mesai saatleri içerisinde veya dışında gerçekleştirilmesi de farklı değerlendirilmelidir. İşyerinde kişisel amaçlarla internet ve sosyal medya kullanımına sınırlama getirilip getirilemeyeceği farklı ülke hukuklarında farklı yorumlanmakta olup, Türk Hukuku'nda da tartışmalıdır. Öğretide bir fikre göre, işverence bu teknolojilerin kullanımının sadece iş amaçlı kullanımla sınırlanması mümkündür (Okur, 2011: 146; Gürsel, 2016: 380). Özel amaçlı kullanım konulu bir düzenleme bulunmadığında kural olarak izin verilmediği ve özel amaçı kullanımı haklı kılacak acil durumlar dışında, özel amaçlarla kullanamayacağı kabul edilmektedir (Okur, 2005: 53; Beytar, 2017: 199). Buna karşılık bizim de taraftarı olduğumuz fikre göre, “... Fransız Hukukunda öne sürülen, işverenin özel amaçlı internet kullanımını tamamen yasaklayamayacağı görüşü, çağın gereklerine daha uygun düşmekte ve hukukumuz bakmandan da kabul edilebilir nitelikte bulunmaktadır." (Özdemir, 2008: 19). Kanaatimizce, iş̧̧inin iletişim olanağının hukuka aykırı sınırlanması veya kaldırılması Anayasa'nın 22. maddesine aykırılık teşkil edeceğinden, işyerinde internet kullanımın sınırlanabilecek ancak tamamen yasaklanamayacaktır (bkz. ve krş. Gürsel, 2016: 383). Bundan işçinin internet kullanma hakkı olduğu ve işyerinde böyle bir olanak sağlamayan işvereni de bunu sağlamaya zorlayabileceği anlaşılmamalıdır. İşveren kişisel kullanıma, süre ve içerik sınırlamaları getirerek doğabilecek risklere karşı gerekli tedbirleri alabilecektir. Belirtelim ki, sanal kaytarma davranışlarının tamamen yasaklanmasının işçinin performansına her zaman olumlu etki etmediği aksine olumsuz etkisinin olduğu savunulmaktadır(Örücü \& Yıldız, 2014: 100). Birleşmiş Milletler İnternet Yönetimi Forumu'nda oluşturulan, İnternet Hak ve İlkeleri Dinamik Koalisyonu (The Internet Rights and Principles Dynamic Coalition) tarafından kabul edilen yol gösterici belge niteliğindeki "İnternette İnsan Hakları ve illkeleri Şartı"nın 14. maddesine göre, "Çalışanlar ve işçiler internet bağlantısı olan her yerde internet erişim hakkına sahiptir. İşyerinde internet kullanımı hakkında herhangi bir kısıtlama olduğunda, bu durum çalışan veya organizasyon ilkelerinde açıkça belirtilmelidir. Çalışanların internet kullanımlarının gözetimi hakkındaki koşullar ve şartlar işyeri ilkeleri kapsamında açıkça belirtilmeli ve veri koruma hakkıyla bağdaşmalıdır.". Düzenleme bağlayıcı nitelik taşımasa da ilerleyen dönemde, ulusal ve uluslararası düzenlemelere yol gösterici olacağı kanaatindeyiz. İnternet erişiminin bir insan hakkı olarak kabulü giderek yaygınlaşmaktadır. İşverence gerçekleştirilecek hukuka aykırı izleme ve gözetleme uygulamaları iş̧̧inin temel hak ve özgürlüklerine müdahale teşkil edecektir. Elektronik gözetimin hukuka uygun olabilmesi için uyulması gereken temel ilke ve esaslara kısaca değinmekle yetineceğiz. İşçinin sosyal medya kullanımının izlemesi, kişilik hakları kapsamında değerlendirilirken, elde edilen verilerin işlenmesikişisel verilerin korunması hukuku açısından değerlendirilmelidir (Beytar, 2017: 195). İzleme ve gözetlemenin amaca uygun ve amaçla sınırlı olması, meşru ve objektif menfaate dayanması, bilgilendirme yapılması, rıza alınması, amaç ve sebeplerin belirtilmesi, gerektiğinde hatırlatma ve uyarılarda bulunulması, kurallara uyulmamasının yaptırımının açıklanması ve savunma imkânının verilmesi gerekir (Sevimli, 2006: 207; Savaş, 2009: 108 vd.; Gürsel, 2016 : 386 vd.; Bozkurt Gümrükçüoğlu, 2017: 82 vd.). Kişisel kullanımı sınırlayan açık düzenleme varsa, işyeri bilgisayarına kayıtlı dosyalar, e-mail ve yazışmaların okunabileceği ancak, e-maillerin veya sosyal medya yazışmalarının takibinde kural olarak, trafik verileri ile sınırlı kalınması gerektiği kabul edilmelidir. Bir başka deyişle, iş̧̧inin aldığı veya gönderdiği e-mail sayısı, gönderi adresleri (Manav, 2015: 125), sosyal medya kullanım süresi, sıklığı, eriş̧im gerçekleştirilen adresler denetlenebilecektir. İşyeri yahut işverene ilişkin olmayan içeriğin denetlenmemesi ve elde edilen veri varsa işlenmemesi gerekmektedir. Zira içerik denetimi işçi dışında iletinin diğer tarafının da özel hayatına müdahale teşkil edeceğinden, zorunlu 
kılan bir sebep olmadıkça başvurulmaması gereken bir yöntemdir. Özel amaçlı kullanıma izin verildiği hallerde işverence kural olarak denetim yapılamaz (Okur, 2006: 8; Bozkurt Gümrükçüoğlu, 2017: 88). Özel bir düzenleme yoksa kanaatimizce, özel kullanıma izin verilmediği değil, izin verildiği kabul edilmelidir. İşyerinde internet erişim olanağı varsa kullanıma ilişkin politikanın belirlenmesi işverenin yükümlülüğüdür. Ancak bazı istisnai durumlarda denetim gerçekleştirilebileceği kabul edilmelidir. Örneğin, suç teşkil eden eylem şüphesi ya da işyeri sırlarının açıklanması tehlikesi vb. gibi durumlarda denetim yapılabilecektir. Yargı kararlarının ise aksi yönde olduğu görülmektedir. Yargıtay 22. H.D. bir kararında "Işverenin kendisine ait bilgisayar ve elektronik posta adresleri ile bu adreslere gelen elektronik postaları her zaman denetleme yetkisi bulunmaktadır. Kaldı ki, davacı iş̧̧inin özel işleri için işverenin izni olmadan bilgisayarı kullanması kabul edilemez. Bu sebeplerle, davalı işverenin bilgisayar verilerine delil olarak dayanmasında hukuka aykıııık bulunmamaktadır..." ifadelerine yer verilmiştir (Yarg. 22. HD, 3.5.2016, E: 2016/6321, K: 2016/13143. Aynı yönde: Yarg. 9. HD, 13.12.2010, E: 2009/447, K: 2010/37516 Kazancı, E.T. 25.03.2018). Böylece işveren izin vermedikçe özel amaçlı kullanıma izin verilmediği ve işverenin denetleyebileceğinin kabul edilmektedir. Iş̧̧inin işyerinde bulunmadığı zamanlarda gerektiğinde, iletişimin sürdürülebilmesi için e-maillerine erişim sağlanması, işçi önceden bilgilendirilmiş ise hukuka uygundur. Belirtmek gerekir ki, 5651 sayılı İnternet Ortamında Yapılan Yayınların Düzenlenmesi ve Bu Yayınlar Yoluyla İşlenen Suçlarla Mücadele Edilmesi Hakkında Kanuna dayanılarak çıkartılan İnternet Toplu Kullanım Sağlayıııları Hakkında Yönetmelik (R.G. 11.04.2017, 30035) gereğince işverenlerin de internet ortamı kullanım imkânı sağlamaları durumunda uymaları gereken yükümlülükler vardır. Yasal yükümlülük gereği gerçekleştirilen denetimlerin meşru kabul edilmesi gerekmektedir. İşverenin gerçekleştirdiği hukuka aykırı denetimin işçi açısından bir fesih sebebi teşkil edip etmeyeceği ise ayrı bir problem teşkil etmektedir. Hukukumuzda genellikle sosyal medya kullanımının işveren açısından fesih nedeni teşkil edip etmeyeceğine ilişkin yargı kararları ile karşılaşılmakla birlikte, ilerleyen dönemde bu gibi problemlerle de karşılaşılacağı kanaatindeyiz. (Benzer bir olay için bkz. Yarg. 7. HD., 09.09.2013 E: 2013/5617, K: 2013/14111 T., Lexpera, E.T. 15.03.2018). Avrupa Birliği 29. Madde Veri Koruma Grubu'nun "Kişisel Verilerin İş İlişkisi Bağlamında Iş̧lenmesi" ve "İşyerinde Elektronik İletişimin İzlenmesi Belgesi"nde izleme politikasının hukuka uygun olabilmesi için, bazı temel ilkelere uyulması gerektiği belirtilmiş olup, bu ilkeler gereklilik, amaçsallık, şeffaflık, meşruluk, ölçülülük, doğruluk, güncellik, verilerin saklanması ve güvenlik ilkelerine uyulması, izleme/gözetlemenin amaca uygun ve mümkün olan en az müdahaleci biçimde gerçekleştirilmesidir. Kanaatimizce, bizim hukukumuzda da izleme ve gözetlemenin bu ilkeler çerçevesinde gerçekleşebileceğine ilişkin yasal düzenleme getirilmesi isabetli olacaktır.iş̧̧inin işyeri yahut işveren ile doğrudan ilişkili olmayan paylaşımları da fesih nedeni teşkil edebilmektedir. Şöyle ki, iş̧̧inin sosyal medyada doğrudan işyeri ile bağlantısı olmasa da kurumsal kimliğe zarar verecek paylaşımlarda bulunması yahut gerçeğe aykırı beyanının yaptığı paylaşımlardan anlaşııması bir fesih nedeni olabilecektir. Örneğin, Yargıtay 9. H.D. bir kararında, işçinin istirahat raporu kullandığı dönemde plajda tatil kıyafetleri ile çekilmiş fotoğraflarını paylaştığı, raporlu olduğunu bildiren iş̧̧inin raporun aksine tatile gitmesi doğruluk ve bağlılı̆a aykırı olduğundan sözleşmesinin işverence haklı nedenle feshinin hukuka uygun olduğuna hükmedilmiştir (06.07.2017, E: 2016/17532, K: 2017/12196, Kazancı, E.T. 09.03.2018). Kanaatimizce de karar isabetlidir. Ayrıca iş̧̧inin içeriği bireysel olsa da belirli bir işyerinin çalışanı olduğunu vurgulayan paylaşımları işverenin kurumsal itibarına zarar verecek nitelikte olduğunda feshe sebep teşkil edebilecektir.

\section{VERI, YÖNTEM, BULGULAR ve ANALIZ}

Türkiye İstatistik Kurumu 2017 yılı Hanehalkı Bilişim Teknolojileri Kullanım Araştırması'na göre, 16-74 yaş grubundaki bireylerde bilgisayar kullanım oranı \%56,6 iken, internet kullanım oranı ise \%66,8 dir (http://www.tuik.gov.tr/HbPrint.do?id=24862 E.T. 01.03.2018). Ülkemizde sosyal medya kullanımı da ciddi ölçüde artmışır ve artmaya devam etmektedir. TUik verilerine göre, bireylerin interneti kişisel kullanım amaçları arasında sosyal medya oldukça önemli bir yer teşkil etmektedir (http://www.tuik.gov.tr/PreTablo.do?alt_id=1028 E.T. 01.03.2018). We Are Social 2018 Raporu'na göre, ülkemizde aktif sosyal medya kullanıcı sayısı 51 milyon olup, toplam nüfusun ortalama \% 54'ü sosyal medya kullanmaktadır. Rapora göre, ülkemiz dünyanın en çok Facebook kullanan 9. ülkesi, İstanbul ise dünyanın en çok Facebook kullanılan 7. şehridir. Ülkemizde en aktif kullanılan sosyal medya platformu \% 55 ile Youtube iken, bunu \% 53 ile Facebook, \% 50 ile Whatsapp izlemektedir (https://digitalreport.wearesocial.com/ E.T. 01.03.2018). Avrupa Birliği verileri ile kıyaslama yapıldığında, 2015 yılının ilk üç ayında ülkemizde internet kullanan bireylerin \%81'i sosyal medya üzerinde profil oluşturma, mesaj gönderme veya fotoğraf vb. içerik paylaşımı amacı ile kullanırken, Avrupa Birliği ortalamasında bu oran \%63 olarak belirlenmiştir. Avrupa Birliği'nde en çok tercih edilen internet kullanım amacı olan e-posta gönderme/alma ortalaması $\% 87$ iken, Türkiye'de ise $\% 49$ olarak tespit edilmiştir. Son zamanlarda işe alım ilanlarının internet siteleri veya sosyal medya aracılığı ile verilmesi giderek yaygınlaşmakta olup, bunun çeşitli nedenleri bulunmaktadır. Bunlardan ilki, diğer yöntemlere nazaran maliyetinin düşüklüğüdür. Maliyetin yanı sıra başka faktörler söz konusudur. Bunlardan belki de en önemlisi, sosyal medya kullanım yoğunluğunun artmasına bağlı olarak, ilanların çok daha fazla sayıda işçi adayına ulaşması ve böylece işverenin seçeneklerinin artmasıdır. Jobvite 2014 verilerine göre, işverenlerin \% 93'ü, işe alım kararı vermeden önce adayın sosyal profilini incelemektedir. Bu çerçevede değerlendirilen hususlardan bazıları profesyonel deneyim, çalıșma süresi, is ile ilgili mesajlar, bağlantılar, özel beceriler, kültürel uyum, örnek teşkil eden çalışmalardır. İşverenlerin \% $55^{\prime}$ i sosyal profillerine göre bir adayı tekrar gözden geçirdiklerini ve bunların \% 61'inin olumsuz sonuçlandığıı ifade etmişlerdir. Adayların iş başvurularının olumsuz sonuçlanmasına yol açan önemli bazı faktörler; küfür, yazım/dilbilgisi, yasa dışı uyuşturucu referansları, cinsel mesajlar, hayır kurumlarına bağışlar, siyasi üyelik, alkol ve silah kullanımıdır (https://www.jobvite.com/wp-content/uploads/2014/10/Jobvite_SocialRecruiting_Survey2014.pdf). Ülkemizde de işverenlerin işe alım kararında sosyal medya araçları üzerinden yaptıkları araştırmalar yaygınlaşmaktadır. Örneğin, Pamukkale Üniversitesi'nde 250 firmada yapılan araştırmaya göre, işverenlerin $\% 69^{\prime} u$ işe alacağı iş̧̧i adaylarına ilişkin bir sosyal medya araştırması yaptıklarını $\% 54,1^{\prime} i$ adayların sosyal medya profilinde gördüklerinden etkilenerek adayı reddettiklerini belirtmişlerdir (http://acikerisim.pau.edu.tr/xmlui/bitstream/handle/11499/2545/Nezehat\%20\%C3\%96zlem\%20Nizamo\%C4\%9Flu.pdf?sequence=1\&isAll owed=y E.T. 05.03.2018). Bu veriler göstermektedir ki, önümüzdeki dönemde işe alım sırasında gerçekleştirilen sosyal medya araştırmalarına bağlı olarak işe alım sürecinde karşılaşılabilecek hukuki problemler artış gösterecektir. Son yıllarda Yargı kararlarına işçinin kişisel internet kullanımına bağlı olarak iş ilişkisinin feshine ilişkin hukuki problemler sıkça yansımaktadır. Örneğin Yargıtay 9. H.D. 2008 yılında vermiş olduğu bir karara göre, "Iş̧̧inin, işverenin açıkça yasaklamasına rağmen interneti özel amaçlı kullanmasında önceden ihtara gerek olmaksızın iş sözleşmesi feshedilebileceği gibi; işçinin pornografik resimleri videoları işletmenin veri taşıyıcısına indirmesi ve yüklemesi halinde ihtara gerek yoktur." (17.3.2008, E: 2007/27583 K: 2008/5294, Kazancı E.T. 20.04.2018). Söz konusu kararda işverence açıkça yasaklanmasına karşılık kişisel amaçla internet kullanımı ve pornografik erişim mevcut olduğundan kanaatimizce de karar isabetlidir. Aynı Dairenin 2011 yılında verdiği bir kararda ise, işçinin mesai saatlerinde makul süreyi aşacak şekilde mesajlaşması ve bu mesajlarda "burası ne tuhaf bir yer dallas gibi, komedi yani, kimin eli kimin cebinde belli değil." gibi sözcüklerle işvereni kötüleyerek itibarını zedelemesi ve böylece tüzel kişiliğin haklarına saldııda 
bulunmasının, dedikodu niteliğini aşan ifadeler olması sebebiyle haklı fesih nedeni olarak nitelendirildiği görülmektedir (03.11.2011, E:2009/25494 K: 2011/42548, http://www.taa.gov.tr/sayfa/bireysel-is-hukuku-11-13-aralik-2015ankara/ E.T. 25.03.2018). Kararda kanaatimizce önemli husus "makul süreyi aşacak" mesajlaşmanın haklı fesih sebebi olarak nitelendirilmesidir. Ancak, makul süre yeterli ölçüde açıklığa kavuşturulmamıștır. Bir diğer husus ise yazışma içeriğinin dedikodu niteliğini aştığı kabul edilerek haklı fesih sebebi olarak değerlendirilmesidir. Karar mefhum-u muhalifinden istihraç suretiyle tefsir edilirse, makul süreyi aşmayan veya dedikodu niteliğini aşmayan kullanımın haklı bir fesih nedeni teşkil etmeyeceği sonucuna ulaşılmaktadır. Ancak dedikodu niteliğinden ne anlaşılması gerektiği ve paylaşım dedikodu niteliğinde olduğu takdirde haklı neden teşkil edecek ağırlıkta olmasa da geçerli neden teşkil edip etmeyeceği anlaşılamamaktadır. Yargıtay 7. HD bir kararında ise şu ifadelere yer verilmiştir; "Facebook' adlı sosyal paylaşım sitesinde ...' isimli bir grup içerisinde yayınlanan 'hasta gelmesin diye dua ederken biz, ..........hastanesi ' başlıkl, davacı ile birlikte 3 kişinin hasta yatakları üzerinde bağdaş kurup oturduğu ve ellerini havaya kaldırarak dua ettikleri fotoğrafın davalı işverence fesih nedeni yapıldığı anlaşılmaktadır. Paylaşılan bu fotoğrafta davalı kurumun isim ve logosu kullanıldığı gibi fotoğrafta davacının üzerinde formasının ve yaka kartının da bulunduğu görülmektedir. Sözü edilen paylaşım 1.285 kişi tarafından beğenilmiş ve fotoğrafın altına 52 yorum yapılmışıır. Fotoğrafın yayınlandığı '...' grubunun yaklaşık 13.102 üyesi olduğu anlaşıımaktadır. Davacının mesai saatleri içerisinde çekilen ve paylaşılacağının bilindiği fotoğraflarının binlerce kişi tarafından izlenebilecek bir sosyal paylaşım sitesinde yayınlanması işyerindeki çalışma disiplinini ve iş akışını etkileyecek nitelikte olup artık davalı işverenden davacı ile çalışması beklenemeyeceğinden somut olayda haklı bir fesih nedeni bulunmasa bile fesih için geçerli bir nedenin bulunduğunun kabulü gerekmektedir." (26.05.2016, E:2016/10461 K. 2016/11592, Lexpera, E.T. 20.03.2018. Kararda kanaatimizce önemli husus, paylaşımın işveren itibarına etkisidir. Paylaşımın yapıldığı grubun üye sayısı ve iş̧̧inin çalıştı̆ı kurumun fotoğraflardan belirlenebilmesi esasları dikkate alınarak değerlendirme yapılmıştır ki, kanaatimizce karara esas yaklaşım isabetlidir. Başka bir olayda Yargıtay 22. H.D. çalışanın sosyal paylaşım sitesinde sadece kendisini takip edenlerin görebileceği ve ağır eleştiri niteliğinde olmakla birlikte ifade özgürlüğü çerçevesinde değerlendirilmesi gereken yazışmalarının işverene geçerli fesih imkânı vermediğine karar vermiştir (14.6.2016, E: 2016/16290, K: 2016/17802, Lexpera). Böylece yargı kararlarında iş̧̧inin sosyal medya paylaşımlarının fesih nedeni teşkil edip etmemesi bakımından değerlendirilirken söz konusu paylaşıma erişim sağlayabilecek kimselerinde önemli olduğu anlaşılmaktadır. Kanaatimizce de, herkesin erişebileceği şekilde gerçekleştirilen paylaşımlarla belirli kişilerin erişebileceği paylaşımlar farklı değerlendirilmelidir. Ancak bazı hallerde iş̧̧inin paylaşımının paylaşım yaptığı grup dışına sızması ve işveren itibarına ciddi zararlar vermesi de söz konusu olabilir. Bu gibi hallerde kanaatimizce somut olayın özellikleri dikkate alınarak paylaşım içeriği, işçinin paylaşımın sızmaması için tedbir alıp almadığı ve işverenin uğradığı yahut uğrama ihtimali olan zarar dikkate alınarak değerlendirme yapılması isabetli olacaktır.

\section{SONUÇ}

Günümüz dünyasında sosyal medya kullanımının tamamen sınırlanması mümkün görülmemektedir. İşverence iş saatlerinde ve işyeri bilgisayarlarında gerçekleştirilebilecek kullanıma sınırlama getirilmesi mümkün olmakla birlikte sosyal medyanın iş ilişkisine yansıması sadece bu nitelikteki kullanımlardan da ibaret değildir. Kanaatimizce, işverenlerce işyerinde internet ve sosyal medya kullanımına ilişkin makul bir politika geliştirilmesi, internet kullanımının bir insan hakkı olduğu tartışmalarının yapıldığı çağımız gereklerine daha uygun olacaktır. Hukuka aykıı, işveren açııından risk doğuracak kullanımın engellenmesi, bunun dışında ise sınırlı sürelerle olsa da kullanıma olanak sağlanması ancak hukuka uygun bir çerçevede denetim gerçekleştirilmesinin daha yararlı olacağı kanaatindeyiz. Ayrıca işçilere verilecek eğitimlerle ve yasa dışı kullanımı engelleyen teknolojik alt yapı ile işletme politikasının desteklenmesi gerektiği kanaatindeyiz.

\section{KAYNAKÇA}

Beytar, E. (2017). İşçinin kişiliğinin ve kişisel verilerinin korunması. İstanbul.

Bozkurt Gümrükçüoğlu, Y. (2017). İş ilişkisinde işçinin kişisel verilerinin korunmasına ilişkin sorunlar ve kişisel verilerin korunması kanunu. İş Hukukunda Genç Yaklaşımlar, İstanbul.

Gürsel, İ. (2016a). Kişisel verilerin korunması hakkının işçi ve işveren ilişkisine etkileri. Legal isGHD, C. 13, S. 50.

Gürsel, İ. (2016). İşçinin kişisel verilerinin korunması hakkı. Ankara.

Güzel, A. (1996). Ekonomik ve teknolojik gelişmelerin ışığında hizmet sözleşmesinin “instuitus personae” niteliği üzerinde yeniden düşünmek. Halid Kemal Elbir' Armağan, İstanbul.

Manav, E. A. (2015). İş ilişkisinde iş̧̧inin kişisel verilerinin korunması. Gazi Üniversitesi Hukuk Fakültesi Dergisi C. XIX, Y. 2015 , S. 2.

Okur, Z. (2005). İşyerinde işçinin bilgisayar ve interneti özel amaçlı kullanımının iş ilişkisine etkisi. Kamu İş, İş Hukuku ve İktisat Dergisi, C.8, S.2, Ankara.

Okur, Z. (2006). Yeni teknoloji ve iş hukuku. Çimento İşveren, C.20, S.3, İstanbul.

Okur, Z. (2011). İş Hukuku'nda elektronik gözetleme. İstanbul.

Örücü, E., Yıldız H. (2014). İşyerinde kişisel internet ve teknoloji kullanımı: sanal kaytarma. Ege Akademik Bakış, Cilt: 14, S. 1, Ocak 2014.

Özdemir, E. (2008). İnternet ve iş sözleşmesi: yeni teknolojilerin iş ilişkisine etkileri üzerine. Sicil İş Hukuku Dergisi, Haziran 2008, S.10.

Savaş, F. B. (2009). İş hukukunda siber gözetim. Çalışma ve Toplum, S.22, İstanbul.

Scholz, M. (2016). Bundesdatenschutzgesetz (BDSG), in Dornbursch, Gregor/Fischermeier, Ernst/Löwisch, Manfred, AR Kommentar zum gesamten Arbeitsrecht, Köln.

Sevimli, K. A. (2006). İşçinin özel yaşamına müdahalenin sınırları. İstanbul. 